\title{
Vertical merger, collusion, and disruptive buyers
}

\author{
Volker Nocke ${ }^{\mathrm{a}, \mathrm{c}, \mathrm{d}, \mathrm{e}, *}$, Lucy White ${ }^{\mathrm{b}, \mathrm{e}}$ \\ a University of Mannheim, Germany

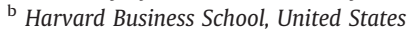 \\ c University of Oxford, United Kingdom

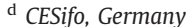 \\ e CEPR, United Kingdom
}

\section{A R T I C L E I N F O}

\section{Article history:}

Received 26 February 2010

Accepted 2 March 2010

Available online 6 March 2010

\section{Jel classifications:}

L13

L42

D43

Keywords:

Vertical merger

Collusion

Disruptive buyer

Merger guidelines

Repeated game

\begin{abstract}
A B S T R A C T
In a repeated game setting of a vertically related industry, we study the collusive effects of vertical mergers. We show that any vertical merger facilitates upstream collusion, no matter how large (in terms of capacity or size of product portfolio) the integrated downstream buyer. But a vertical merger with a larger buyer helps more to facilitate upstream collusion than a similar merger with a smaller buyer. This formalizes the idea expressed in the U.S. and EU Non-Horizontal Merger Guidelines that some downstream buyers may be more "disruptive" of collusive schemes than others.
\end{abstract}

(C) 2010 Elsevier B.V. All rights reserved.

\section{Introduction}

The current U.S. and EU Non-Horizontal Merger Guidelines both point to the idea that vertical mergers may facilitate collusion between upstream firms. This idea has recently been given theoretical underpinnings by Nocke and White (2007) and Normann (2009). Both of these papers use models of symmetric upstream and downstream firms to demonstrate that, in an unintegrated industry, any vertical merger will facilitate upstream collusion. ${ }^{1}$ Antitrust authorities however, have highlighted the idea that vertical mergers may be used to remove particularly disruptive buyers. For example, the U.S. Non-Horizontal Merger Guidelines, adopted in 1984, state:2

The elimination by vertical merger of a particularly disruptive buyer in a downstream market may facilitate collusion in the upstream market. If upstream firms view sales to a particular buyer as sufficiently important, they may deviate from the terms of a collusive agreement in an effort to secure that business, thereby disrupting the

\footnotetext{
* Corresponding author. University of Mannheim, Germany.

E-mail addresses: nocke@uni-mannheim.de (V. Nocke), lwhite@hbs.edu (L. White).

${ }^{1}$ Nocke and White (2007) derive this result for the case where upstream firms compete in (efficient) nonlinear contracts. Normann (2009) shows that the result obtains even when upstream firms are restricted to offer (inefficient) linear contracts.

2 The new (2008) EU Non-Horizontal Merger Guidelines more or less paraphrase the 1984 U.S. guidelines.
}

operation of the agreement. The merger of such a buyer with an upstream firm may eliminate that rivalry, making it easier for the upstream firms to collude effectively.

In this paper we attempt to offer some guidance as to which vertical mergers should particularly be avoided. We extend the model of Nocke and White (2007) by allowing downstream firms to differ in their capacities or in the size of their product portfolios and we examine which downstream mergers most facilitate collusion.

Our findings are in line with the Non-Horizontal Merger Guidelines' suggestion that large buyers (whether in terms of capacity or in terms of the size of their product portfolios) are especially disruptive to collusive schemes. However, the reasoning behind our findings is slightly different from the intuition outlined above. In our model, when an upstream firm considers deviating from a collusive agreement, it would ideally like to be able to sell at lower prices to all downstream firms in order to maximize its deviation profit. If one of the downstream firms is vertically integrated, this creates what Nocke and White (2007) call an outlets effect - the vertically integrated downstream firm is no longer available as an outlet for the sales of the deviating upstream firm. Intuitively, the larger the integrated downstream firm's capacity, the larger the outlets effect and the more the incentive of unintegrated upstream firms to cheat on the collusive agreement is reduced. But this does not automatically imply that a merger with the largest 
downstream firm most facilitates collusion since this merger also generates the largest punishment effect. That is, integration increases the temptation of the vertically integrated firm to cheat because when it owns a downstream firm it can also earn profits in the punishment phase - and it can earn (weakly) larger profits the larger its downstream affiliate is. We show, however, that as the size of the integrated downstream unit increases, the size of the outlets effect increases faster than the size of the punishment effect. Therefore, integrating with a larger unit most facilitates collusion.

The plan of the paper is as follows. In Section 2, we set out the baseline model where upstream and downstream firms make their pricing/output decisions at the same time and different downstream firms are endowed with different capacities. We derive the equilibrium of the game in Section 3. We then briefly explore two extensions of our baseline model in Section 4. First, we analyze the case of sequential timing (where downstream firms make their output decisions only after observing upstream firms' contract offers) and second, we consider the case of differentiated goods downstream (where downstream buyers differ in the size of their product portfolios). Section 5 concludes.

\section{The baseline model}

We consider a vertically related industry with $M \geq 2$ upstream firms, $U_{1}$ to $U_{M}$, and $N \geq 2$ downstream firms, $D_{1}$ to $D_{N}{ }^{3}$ The upstream firms produce a homogeneous input at constant marginal cost, normalized to zero, which they sell to the downstream firms. The downstream firms transform this input into a homogeneous final good, on a one-to-one basis, at zero cost (but subject to a capacity constraint); the final good is sold on to consumers.

The upstream firms compete in two-part tariff contract offers of the form $\left(F_{i j}, w_{i j}\right)$, where $F_{i j}$ is the fixed (or franchise) fee and $w_{i j}$ the (marginal) wholesale price that $U_{i}$ offers to $D_{j}$. ${ }^{4}$ The downstream firms compete in quantities in the downstream (or retail) market, but face (exogenous) capacity constraints. Specifically, $D_{j}$ is endowed with capacity $\mathrm{k}_{\mathrm{j}}$, so that aggregate capacity is equal to $K=\sum_{j=1}^{N} k_{j}$. Inverse demand in the downstream market is given by $P(Q)$, where $Q=\sum_{j=1}^{N} q_{j}$ is aggregate output and $q_{j} \leq k_{j}$ downstream firm $D_{j}$ 's output. We impose standard assumptions on demand. Specifically, for any $Q$ such that $P(Q)>0$, demand is downward-sloping, $P^{\prime}(Q)<0$, and not too convex, $P^{\prime}(Q)+Q P^{\prime \prime}(Q)<0$ (implying that quantities are strategic substitutes in the downstream market), with marginal revenue $d[Q P(Q)] / d Q$ being positive for $Q$ sufficiently small and negative for $Q$ sufficiently large. ${ }^{5}$

The upstream and downstream firms play an infinitely-repeated game. The stage game consists of two stages:

Pricing stage: The upstream firms simultaneously announce twopart tariff contract offers at the same time as the downstream firms simultaneously announce quantities.

Acceptance stage: The downstream firms simultaneously decide which contract offer(s) to accept. ${ }^{6}$

Each firm seeks to maximize its expected discounted profit. The common discount factor is denoted by $\delta$. Vertical integration means

\footnotetext{
${ }^{3}$ The model closely follows the baseline model of Nocke and White (2007), except that (i) downstream firms face capacity constraints (which vary across firms) and (ii) we restrict attention to homogeneous final goods.

${ }^{4}$ Upstream firms are not required to make the same offer to all downstream firms.

${ }^{5}$ It is well known that, under these conditions, there exists a unique Nash equilibrium in the associated Cournot game where all (downstream) firms face constant marginal costs of production (wholesale prices).

${ }^{6}$ At the beginning of the stage, before acceptance decisions are made, a public random variable is realized. The role of this public randomization is to facilitate the arbitrary sharing of any collusive profits amongst upstream firms.
}

that all affiliates share the same objective function. This implies, in particular, that internal transfer prices do not affect behavior: when procuring from its upstream affiliate, the effective wholesale price that a vertically integrated downstream firm faces is the upstream affiliate's marginal cost (assumed to be zero).

It is straightforward to verify that the stage game has a subgameperfect equilibrium in which all upstream firms (competing in a Bertrand-type fashion) offer the contract $(0,0)$ to all downstream firms, and the downstream firms set quantities corresponding to the equilibrium quantities in the associated Cournot game where all (downstream) firms have zero marginal costs. In this noncollusive equilibrium, each upstream firm makes zero profit while downstream firm $D_{j}$ 's profit is $\pi_{j}^{n c}=q_{j}^{n c} P\left(Q^{n c}\right)$, where $q_{j}^{\text {nc }}$ denotes $D_{j}$ 's equilibrium output and $Q^{\text {nc }}$ aggregate output. Note that this equilibrium outcome is independent of market structure (the extent of vertical integration), provided neither the upstream nor the downstream market is monopolized.

In the collusive equilibrium we study, the upstream firms collectively extract all of the monopoly rents, $\Pi^{m}$. This is achieved by making contract offers that induce the downstream firms to collectively produce the monopoly quantity $Q^{m} \equiv \max _{Q} Q P(Q)$. We assume that this perfectly collusive outcome is sustained by the threat of infinite reversion to the noncollusive equilibrium in case an upstream firm (or an integrated downstream affiliate) deviates; a deviation by an unintegrated downstream firm does not trigger any punishment. ${ }^{7}$ We will say that a vertical merger facilitates upstream collusion if it reduces the 'critical discount factor' above which the perfectly collusive outcome can be sustained. A vertical merger facilitates collusion more than another merger if it results in a lower critical discount factor.

To make the sustainability of collusion nontrivial, we assume that industry capacity strictly exceeds the monopoly level, $K>Q^{m}$. For simplicity, we also assume that no firm can produce the monopoly quantity on its own, $\max _{i} k_{i}<Q^{m}$, and that each downstream firm $D_{j}$ faces a binding capacity constraint in the noncollusive equilibrium, $q_{j}^{n c}=k_{j}$, so that $\pi_{j}^{n c}=P(K) k_{j}$.

\section{Equilibrium analysis}

In this section, we study the effect of a vertical merger on the sustainability of upstream collusion. We show that a vertical merger with a larger downstream firm (one with a larger capacity) does more to facilitate upstream collusion in that it results in a lower critical discount factor.

Consider first the case where no firm is vertically integrated. An upstream firm can deviate from the collusive agreement by slightly undercutting its rivals' collusive contract offers, thereby gaining the business of the $N$ downstream firms and fetching a deviation profit that is arbitrarily close to the monopoly profit $\Pi^{m}$. In the ensuing infinite punishment phase, the deviant upstream firm will make zero profit. Since upstream firms are symmetric, the optimal collusive agreement involves the upstream firms sharing the collusive pie equally. The nocheating constraint is thus given by

$$
\frac{\Pi^{m}}{M(1-\delta)} \geq \Pi^{m}
$$

As in the textbook Bertrand model, the resulting critical discount factor (above which perfect collusion can be sustained) is

$\hat{\delta}_{0}=\frac{M-1}{M}$.

${ }^{7}$ We do not study the issue of optimal punishment in this paper. As shown in Mailath et al. (2004), the logic of simple penal codes breaks down in repeated extensive-form games such as the one considered here. 
Suppose now that a single upstream-downstream pair, say $U_{1}-$ $D_{j}$, is vertically integrated. As shown in Nocke and White (2007), there are two countervailing effects on the sustainability of upstream collusion. On the one hand, following any deviation, the vertically integrated firm captures the noncollusive profit of its downstream affiliate, $\pi_{j}^{n c}$, in the punishment phase. Holding fixed its collusive market share, $U_{1}$ therefore has a greater incentive to cheat if it is vertically integrated. We call this the punishment effect of vertical integration. $U_{1}-D_{j}$ 's incentive constraint is given by

$$
\frac{\alpha_{j} \Pi^{m}}{1-\delta} \geq \Pi^{m}+\underbrace{\frac{\delta}{1-\delta} \pi_{j}^{n c}}_{\text {punishment effect }},
$$

where $\alpha_{\mathrm{j}}$ is the integrated firm's share of the collusive pie.

On the other hand, a deviant unintegrated upstream firm, say $U_{i}$, $i>1$, cannot get the business of the integrated $D_{j}$ as $D_{j}$ internalizes any externality on its upstream affiliate $U_{1}$ that accepting such a deviant contract offer would have. Put differently, the integrated $D_{j}$ can get the input from its own upstream affiliate at marginal cost (zero) and is therefore not willing to pay any more to the deviant $U_{i}$. As a result, $U i$ 's maximal deviation profit is $\left[1-\left(q_{j}^{*} / Q^{m}\right)\right] \Pi^{m}$, where $q_{j}^{*}$ is the quantity sold through $D_{j}$ along the collusive equilibrium path. Hence, vertical integration reduces the number of downstream outlets through which an upstream rival can deviate, thereby reducing that firm's deviation profit. We call this the outlets effect of vertical integration. From the viewpoint of sustaining upstream collusion, it is optimal to maximize the outlets effect by having $q_{j}^{*}$ as large as possible, $q_{j}^{*}=k_{j}$, with the $N-1$ unintegrated downstream firms jointly selling $Q^{m}-k_{j}$, and letting the $M-1$ unintegrated upstream firms each obtain the same share of the collusive profit. In that case, the unintegrated $U_{\mathrm{i}}$ 's incentive constraint is

$$
\frac{\left(1-\alpha_{j}\right) \Pi^{m}}{(M-1)(1-\delta)} \geq \Pi^{m}-\underbrace{\frac{k_{j}}{Q^{m}} \Pi^{m}}_{\text {outlets effect }}
$$

Pooling the $M$ incentive constraints, we obtain the critical discount factor for the case when $U_{1}-D_{j}$ is vertically integrated:

$$
\hat{\delta}_{j}=\frac{M-1}{M+\frac{\frac{k_{j}}{Q^{m}} \Pi^{m}-\pi_{j}^{n c}}{\left(1-\frac{k_{j}}{Q^{m}}\right) \Pi^{m}} .}
$$

Since $\left(k_{j} / Q^{m}\right) \Pi^{m}-\pi_{j}^{n c}=k_{j}\left[P\left(Q^{m}\right)-P(K)\right]>0$, we have $\hat{\delta}_{\mathrm{j}}<(M-1) /$ $M=\hat{\delta}_{0}$. That is, the vertical merger of $U_{1}$ with $D_{j}$ facilitates upstream collusion as the outlets effect outweighs the punishment effect, no matter what the size of the downstream firm. This extends the result of Nocke and White (2007) to the case of heterogeneous downstream firms. The more interesting question, though, is whether the U.S. and EU Non-Horizontal Merger Guidelines are correct in stating that a vertical merger with a larger downstream firm facilitates upstream collusion more than a vertical merger with a smaller buyer. The following proposition answers this question affirmatively:

Proposition 1. A vertical merger facilitates upstream collusion, no matter what the size of the integrated downstream firm. A vertical merger with a larger downstream firm facilitates upstream collusion more than a vertical merger with a smaller downstream firm:

$$
k_{l}>k_{j} \Rightarrow \hat{\delta}_{l}<\hat{\delta}_{j}
$$

Proof. Since $k_{1}=k_{j}$ implies $\hat{\delta}_{1}=\hat{\delta}_{\mathrm{j}}$, it suffices to show that

$\left.\frac{d}{d k_{j}}\left(\frac{\frac{k_{j}}{Q^{m}} \Pi^{m}-\pi_{j}^{n c}}{\left(1-\frac{k_{j}}{Q^{m}}\right) \Pi^{m}}\right)\right|_{K=\text { const. }}>0$

over the relevant range. (The case of no vertical integration is isomorphic to the case where the vertically integrated downstream firm has no capacity, $k_{j}=0$.) Indeed, Eq. (1) can be rewritten as

$$
\left[P\left(Q^{m}\right)-P(K)\right]\left(1-\frac{k_{j}}{Q^{m}}\right)+P\left(Q^{m}\right) k_{j}\left[P\left(Q^{m}\right)-P(K)\right]>0 .
$$

But this last inequality must hold as $P\left(Q^{m}\right)>P(K)$ and $k_{j} \leq Q^{m}$.

The intuition for this result can perhaps best be given by a simple example. Suppose $N=2$ with $k_{1}=0.8 \times Q^{m}$ and $k_{2}=0.4 \times Q^{m}$, i.e., $D_{1}$ is twice as large (in terms of capacity) as $D_{2}$. Since both firms face a binding capacity constraint in the noncollusive equilibrium, the punishment effect (for a fixed discount factor) is twice as large under vertical integration with $D_{1}$ as under vertical integration with $D_{2}$. What about the relative sizes of the outlets effect? Under vertical integration $U_{1}-D_{1}$, an unintegrated $U_{\mathrm{i}}$ can get only $20 \%$ of the monopoly profit in the period of deviation. In contrast, under vertical integration $U_{1}-D_{2}$, a deviant unintegrated $U_{\mathrm{i}}$ can get three times as much, namely $60 \%$ of the monopoly profit. $^{8}$

Remark: Above, we have assumed that downstream firms compete in quantities. It is straightforward to show that Proposition 1 continues to hold if downstream competition is in prices rather than quantities, provided any rationing is efficient. In fact, under Bertrand competition with efficient rationing, the incentives to deviate are exactly as under Cournot competition.

\section{Extensions}

In this section, we study two model extensions: the case of sequential timing within each period, and the case of differentiated final goods where downstream firms differ in the size of their product portfolios.

\subsection{Cournot sequential timing}

In the baseline model, we assumed that the downstream firms make their output decisions at the same time as the upstream firms make their contract offers. We now consider the case of sequential timing where the upstream firms make their two-part tariff contract offers first, then the downstream firms publicly decide which contract(s) to accept and then compete in quantities. That is, the sequence of moves in each period is as follows:

Contract offer stage: The upstream firms simultaneously announce two-part tariff contract offers.

Acceptance stage: The downstream firms simultaneously decide which contract offer(s) to accept. ${ }^{9}$

Output stage: The downstream firms simultaneously set quantities.

As in the baseline model, the noncollusive equilibrium involves zero profit for each upstream firm and profit $\pi_{j}^{n c}>0$ for each downstream firm $D_{j}$. We assume again that $K>Q^{m}>\max _{j} k_{j}$ and that $\pi_{j}^{n c}=P(K) k_{j}$ for each $D_{j}$.

Suppose there is a single vertically integrated upstream-downstream pair, say $U_{1}-D_{j}$. The incentive constraint of the vertically

\footnotetext{
${ }^{8}$ From this argument, it should also be clear that the result would carry over to the case where not all downstream firms face a binding capacity constraint in the noncollusive equilibrium as, in that case, the punishment effect would rise less-thanproportionately with capacity.

${ }_{9}^{9}$ As in the baseline model, there is a public randomization device at the beginning of the stage.
} 
integrated firm is as in the baseline model:

$$
\frac{\alpha_{j} \Pi^{m}}{1-\delta} \geq \Pi^{m}+\underbrace{\frac{\delta}{1-\delta} \pi_{j}^{n c}}_{\text {punishment effect }}
$$

where $\alpha_{\mathrm{j}}$ is again the integrated firm's share of the collusive pie. ${ }^{10}$ As before, we have the punishment effect of vertical integration (which makes collusion harder).

Consider now the incentives to deviate for an unintegrated upstream firm, say $U_{\mathrm{i}}$. For the same reason as before, the deviant $\mathrm{U}_{\mathrm{i}}$ cannot profitably sell through the integrated $D_{j}$. If the downstream quantities were fixed at their collusive levels (as they effectively are in the baseline model) and if $D_{j}$ uses all of its capacity along the collusive equilibrium path (which is weakly optimal), then $U_{i}$ 's deviation profit is reduced by $\left(k_{j} / Q^{m}\right) \Pi^{m}$ (relative to the situation without vertical integration). This is the by now familiar outlets effect of vertical integration (which makes collusion easier). However, the downstream quantities are not fixed at their collusive levels in the sequential model as the downstream firms set their quantities after observing all contract offers and all acceptance decisions. The resulting impact on an unintegrated upstream firm's deviation profit is called the reaction effect of vertical integration. In particular, observing $U_{i}$ 's deviant contract offers (and, therefore, knowing that collusion will break down anyway), the integrated $D_{j}$ will optimally set the myopic Cournot best-response output to the output produced by the $N-1$ unintegrated downstream firms, subject to the capacity constraint $q_{j} \leq k_{j}$. It is straightforward to show that $D_{j}$ will indeed operate at its capacity limit (which it also does, by assumption, in the noncollusive equilibrium). ${ }^{11}$ Hence, $U_{i}$ 's maximal deviation profit is given by

$\pi_{i}^{\operatorname{dev}}\left(k_{j}\right) \equiv \max _{q \leq K-k_{j}} P\left(k_{j}+q\right) q$

The incentive constraint can thus be written as:

$$
\frac{\left(1-\alpha_{j}\right) \Pi^{m}}{(M-1)(1-\delta)} \geq \Pi^{m}-\underbrace{\frac{k_{j}}{Q^{m}} \Pi^{m}}_{\text {outlets effect }}-\underbrace{\left[\left(1-\frac{k_{j}}{Q^{m}}\right) \Pi^{m}-\pi_{i}^{\text {dev }}\left(k_{j}\right)\right]}_{\text {reaction effect }} .
$$

In contrast to Nocke and White (2007), the reaction effect is actually negative here: the fact that downstream firms can adjust their quantities in response to $U_{i}$ 's deviation unambiguously benefits the deviant $U_{i}$. The reason is that the integrated $D_{j}$ is capacity constrained anyway (if the outlets effect is to be maximized), while the Cournot best-response output to $k_{j}$ is strictly more than what the unintegrated downstream firms jointly produce in the collusive equilibrium (which is $Q^{m}-k_{j}$ ). Of course, vertical integration still reduces the deviation profit of any

\footnotetext{
10 To see that the deviation profit of the integrated $U_{1}-D_{j}$ is not less than $\Pi^{m}$, note that there is no 'lack-of-commitment effect' as the deviant integrated firm can credibly commit not to sell more than $k j$ through its own downstream affiliate. To see that the deviation profit is not more than $\Pi^{m}$, note that the integrated firm cannot deviate "secretly" by only increasing its own downstream affiliate's output (without changing any contract offer) if the affiliate faces a binding capacity constraint along the collusive equilibrium path. (From the viewpoint of sustaining upstream collusion, it is indeed weakly optimal to have the integrated downstream affiliate operate at its capacity limit.)

${ }^{11}$ To see this, note that the $N-1$ unintegrated downstream firms cannot jointly sell more than they do in the noncollusive equilibrium, $K-k_{j}$, as they are capacity constrained in that equilibrium. Since our assumption on demand implies that quantities are strategic substitutes, this means that $D j$ must still be capacity constrained if the $N-1$ downstream rivals jointly produce less than $K-k_{\text {. }}$. By offering the appropriate contracts to the unintegrated downstream firms, the deviant $U_{i}$ can induce any feasible vector of quantities $\left(q_{l}\right)_{l \neq \mathrm{j}}$, and extract all of the unintegrated downstream firms' rents.
}

unintegrated upstream firm, $\pi_{i}^{d e v}\left(k_{j}\right)<\Pi^{m}$, as the integrated $D_{j}$ sells $\mathrm{k}_{\mathrm{j}}>0$ units of output and the deviant $U_{i}$ cannot capture the associated rent.

Summing up the incentive constraints and solving for $\delta$, yields the critical discount factor above which perfect collusion can be sustained:

$$
\widehat{\delta}_{j}=\frac{M-1}{M+\frac{\Pi^{m}-\pi_{j}^{n c}-\pi_{i}^{d e v}\left(k_{j}\right)}{\pi_{i}^{d e v}\left(k_{j}\right)}} .
$$

In addition to the two opposing effects from the baseline model (with simultaneous timing), the punishment and outlets effects, there is a new effect, the reaction effect. Even though the reaction effect raises the deviation profit of an unintegrated upstream firm, thereby making collusion harder to sustain, the net effect of a vertical merger is to facilitate upstream collusion. Does vertical integration with a larger downstream buyer help more in facilitating upstream collusion? Even though a vertical merger with a larger downstream firm results in a larger (more negative) reaction effect, we obtain the same result as in the baseline model:

Proposition 2. In the sequential model, a vertical merger facilitates upstream collusion, no matter what the size of the integrated downstream firm. A vertical merger with a larger downstream firm facilitates upstream collusion more than a vertical merger with a smaller downstream firm:

$k_{l}>k_{j} \Rightarrow \hat{\delta}_{l}<\hat{\delta}_{j}$

Proof. See Nocke and White (2010).

\subsection{Differentiated final goods}

We now return to the simultaneous timing of the baseline model but assume that final goods are symmetrically differentiated with downstream competition being either in quantities or prices. ${ }^{12}$ Instead of assuming that downstream firms are capacity constrained, we posit that they differ in the number of final goods they sell. Specifically, downstream firm $D_{j}$ sells $k j$ (symmetric) final goods. Each final good is offered by at most one downstream firm so that $K=\sum_{\mathrm{j}=1}^{N} k_{j}$ is the total number of final goods. We assume that the symmetric demand system is well behaved so that the monopoly outcome is well defined and symmetric, and that, for any vector of contract offers, there exists a unique and stable Nash equilibrium in the associated downstream competition game. ${ }^{13}$ As before, $\pi_{j}^{n c}$ denotes $D_{j}$ 's profit (from all of its goods) in the noncollusive equilibrium. We assume that demand can be smoothly parameterized by the degree of product differentiation $\sigma \in(0,1)$, where $\sigma \rightarrow 0$ means that goods become independent (so that $\sum_{j=1}^{N} \pi_{j}^{n c} / \Pi^{m} \rightarrow 1$ and $\pi_{l}^{n c}$ / $\left.\sum_{j=1}^{N} \pi_{j}^{n c} \rightarrow k_{l} / K\right)$ and $\sigma \rightarrow 1$ means that goods become perfect substitutes. We assume that the ratio $\pi_{i}^{N C} / \Pi^{M}$ is decreasing in $\sigma$ (since competition becomes more intense as goods become closer substitutes); this assumption holds for standard symmetric demand systems.

Consider the case of a single vertical merger, say $U_{1}-D_{j}$. The integrated firm's incentive constraint can again be written as

$$
\frac{\alpha_{j} \Pi^{m}}{1-\delta} \geq \Pi^{m}+\underbrace{\frac{\delta}{1-\delta} \pi_{j}^{n c}}_{\text {punishment effect }}
$$

\footnotetext{
12 Due to shortage of space, we provide only a rough model description and heuristic analysis.

${ }^{13}$ See Vives (2001) for sufficient conditions on the demand system; see also Kühn (forthcoming) who uses such a demand system to study the collusive effects of horizontal mergers. Well-known examples of demand systems satisfying our requirements include the Dixit-Stiglitz CES and Bowley's linear-quadratic demand systems.
} 
In contrast to the baseline model (and the sequential model) where all firms face a binding capacity constraint in the noncollusive equilibrium, the size of the punishment effect rises less-thanproportionately with the size $k j$ of the integrated downstream firm:

$k_{l}>k_{j} \Rightarrow \frac{\pi_{l}^{n c}}{k_{l}}<\frac{\pi_{j}^{n c}}{k_{j}}$.

This is for two reasons. First, and most importantly, a downstream firm that sells more goods than another will charge a higher price for (or sell a smaller quantity of) each one of its goods as the firms internalize the positive externality that a higher price has on the demand of their other goods. Hence, the more goods a downstream firm has in its portfolio, the more is the price of each good biased away from the price that would maximize the profit from that good, holding all other prices fixed. Second, a smaller firm faces on average higher rival prices than a larger firm precisely because larger firms charge higher prices. ${ }^{14}$

The incentive constraint of an unintegrated upstream firm, say $U_{i}$, can be written as:

$$
\frac{\left(1-\alpha_{j}\right) \Pi^{m}}{(M-1)(1-\delta)} \geq \Pi^{m}-\underbrace{\frac{k_{j}}{K} \Pi^{m}}_{\text {outlets effect }} .
$$

Note that the outlets effect is proportional to the size of the downstream firm as, in the collusive equilibrium, each final good fetches $(1 / K)$-th of the monopoly revenue.

Summing up the $M$ incentive constraints and solving for $\delta$, yields the critical discount factor

$\hat{\delta}_{j}=\frac{M-1}{M+\frac{k_{j} \Pi^{m}-\Pi_{j}^{n c}}{\left(1-\frac{k_{j}}{K}\right) \Pi^{m}} .}$

Since the punishment effect rises less-than-proportionately with $k_{j}$ while the outlets effect is proportional to $k_{j}$, we obtain the same result as before:

Proposition 3. In the model with differentiated final goods, a vertical merger facilitates upstream collusion, no matter what the size of the integrated downstream firm. A vertical merger with a larger downstream firm facilitates upstream collusion more than a vertical merger with a smaller downstream firm:

$k_{l}>k_{j} \Rightarrow \hat{\delta}_{l}<\hat{\delta}_{j}$.

Proof. See Nocke and White (2010).

\section{Conclusion}

The U.S. and EU Non-Horizontal Merger Guidelines both explicitly refer to the idea that some downstream buyers may be more "disruptive" of collusive schemes than others. In this paper, we try to understand better which vertical mergers should be of particular concern for antitrust authorities worried about the effects of such mergers on upstream collusion. Building on Nocke and White (2007), we have analyzed a series of models focusing on two types of downstream heterogeneity: downstream firms' capacity level (when final goods are homogeneous) and the size of downstream firms' product portfolio (when final goods are differentiated). In each case, our findings are in line with the suggestion in the Guidelines that it is likely that a vertical merger with a larger downstream buyer (i.e., one with greater capacity or more products) has a greater potential to facilitate upstream collusion than a similar merger with a smaller buyer.

The reason behind our finding is the following. When a merger occurs, there are at least two important effects. First, upstream firms which are not party to the merger will typically not be able to sell to the integrated downstream buyer when they choose to deviate from any collusive agreement (because doing so would alert the integrated firm to the deviation). This outlets effect makes collusion easier by reducing the deviation profits of the non-merging upstream firms and it is increasing in the size of the integrated downstream affiliate. On the other hand, there is a counter-acting punishment effect, which makes collusion harder by reducing the severity of the punishment which can be meted out to the merging firms should they cheat on the agreement. The ability to sell through a downstream affiliate allows the merging upstream firm to make profits in the punishment phase, and the larger the downstream affiliate, the greater the profits, increasing the integrated firm's temptation to cheat on any collusive agreement. It can be shown that the outlets effect outweighs the punishment effect, so that any vertical merger facilitates upstream collusion (Nocke and White, 2007). In addition, we show that the outlets effect grows faster than the punishment effect with the size of the merging downstream firm. This implies that larger buyers are more disruptive in that the reduction in the critical discount factor above which perfect upstream collusion can be sustained is greater when the merging downstream buyer is larger. ${ }^{15}$

Therefore, if an antitrust authority is concerned that upstream collusion is a possibility, then, other things being equal, it should be particularly wary of mergers with large buyers. Our analysis also suggests that in these circumstances, an appropriate response to such a merger might be to require the merging firms to divest part of their downstream capacity or some of their downstream products before allowing the merger.

\section{References}

Compte, O., Jenny, F., Rey, P., 2002. Capacity constraints, mergers and collusion. European Economic Review 46 (1), 1-29.

Kühn, K.-U., forthcoming. The coordinated effects of mergers in differentiated products markets. RAND Journal of Economics.

Kühn, K.-U., Rimler, M.S., 2006. The comparative statics of collusion models. CEPR Discussion Paper DP5742. Centre for Economic Policy Research.

Mailath, G.J., Nocke, V., White, L., 2004. When the punishment must fit the crime: remarks on the failure of simple penal codes in extensive-form games. CEPR Discussion Paper 4793. Centre for Economic Policy Research.

Nocke, V., White, L., 2007. Do vertical mergers facilitate upstream collusion? American Economic Review 97 (4), 1321-1339.

Nocke, V., White, L., 2010. Vertical merger, collusion, and disruptive buyers. CEPR Discussion Paper DP7722. Centre for Economic Policy Research.

Normann, H.-T., 2009. Vertical mergers, raising rival's cost and upstream collusion. European Economic Review 53 (4), 461-480.

Vives, X., 2001. Oligopoly Pricing: Old Ideas and New Tools. MIT Press.

\footnotetext{
${ }^{14}$ See Kühn and Rimler (2006) for a more formal proof.
}

\footnotetext{
${ }^{15}$ In a sense, this means that a more asymmetric market structure - where the sole vertically integrated firm is larger - is more conducive to collusion. In contrast, the literature on the collusive effects of horizontal mergers suggests that a more asymmetric market structure makes collusion harder to sustain; see Compte et al. (2002) and Kühn (forthcoming).
} 